\title{
Lipid-dependent control of hepatic glycogen stores in healthy humans
}

\author{
H.Stingl ${ }^{1}$, M. Krššák ${ }^{1}$, M. Krebs ${ }^{1}$, M. G. Bischof ${ }^{1}$, P. Nowotny ${ }^{1}$, C.Fürnsinn ${ }^{1}$, G. I. Shulman ${ }^{2}$, W. Waldhäusl ${ }^{1}$, \\ M. Roden ${ }^{1}$ \\ ${ }^{1}$ Divison of Endocrinology and Metabolism, Department of Internal Medicine III, University of Vienna Medical School, \\ Vienna, Austria \\ ${ }^{2}$ Howard Hughes Medical Institute, Department of Internal Medicine, Yale University School of Medicine, New Haven, \\ Connecticut, USA
}

\section{Abstract}

Aims/hypothesis. Non-esterified fatty acids and glycerol could stimulate gluconeogenesis and also contribute to regulating hepatic glycogen stores. We examined their effect on liver glycogen breakdown in humans.

Methods. After an overnight fast healthy subjects participated in three protocols with lipid/heparin (plasma non-esterified fatty acids: $2.2 \pm 0.1 \mathrm{~mol} / \mathrm{l}$; plasma glycerol: $0.5 \pm 0.03 \mathrm{~mol} / \mathrm{l} ; \quad n=7)$, glycerol $(0.4 \pm$ $0.1 \mathrm{~mol} / \mathrm{l} ; 1.5 \pm 0.2 \mathrm{~mol} / \mathrm{l} ; n=5)$ and saline infusion (control; $0.5 \pm 0.1 \mathrm{~mol} / \mathrm{l} ; 0.2 \pm 0.02 \mathrm{~mol} / \mathrm{l} ; n=7$ ). Net rates of glycogen breakdown were calculated from the decrease of liver glycogen within $9 \mathrm{~h}$ using ${ }^{13} \mathrm{C} \mathrm{nu}-$ clear magnetic resonance spectroscopy. Endogenous glucose production was measured with infusion of D- $\left[6,6-{ }^{2} \mathrm{H}_{2}\right]$ glucose.

Results. Endogenous glucose production decreased by about $25 \%$ during lipid and saline infusion $(p<0.005)$ but not during glycerol infusion $(p<0.001$ vs lipid, sa- line). An increase of plasma non-esterified fatty acids or glycerol reduced the net glycogen breakdown by about $84 \%$ to $0.6 \pm 0.3 \mu \mathrm{mol} \cdot \mathrm{kg}^{-1} \cdot \min ^{-1}(p<0.001$ vs saline: $\left.3.7 \pm 0.5 \mu \mathrm{mol} \cdot \mathrm{kg}^{-1} \cdot \mathrm{min}^{-1}\right)$ and by about $46 \%$ to $2.0 \pm 0.4 \mu \mathrm{mol} \cdot \mathrm{kg}^{-1} \cdot \mathrm{min}^{-1}(p<0.01$ vs saline and lipid), respectively. Rates of gluconeogenesis increased to $11.5 \pm 0.8 \mu \mathrm{mol} \cdot \mathrm{kg}^{-1} \cdot \min ^{-1}(p<0.01)$ and $12.8 \pm 1.0 \mu \mathrm{mol} \cdot \mathrm{kg}^{-1} \cdot \mathrm{min}^{-1}(p<0.01$ vs saline: $8.2 \pm$ $\left.0.7 \mu \mathrm{mol} \cdot \mathrm{l}^{-1} \cdot \mathrm{min}^{-1}\right)$, respectively.

Conclusion/interpretation: An increase of non-esterified fatty acid leads to a pronounced inhibition of net hepatic glycogen breakdown and increases gluconeogenesis whereas glucose production does not differ from the control condition. We suggest that this effect is not due to increased availability of glycerol alone but rather to lipid-dependent control of hepatic glycogen stores. [Diabetologia (2001) 44: 48-54]

Keywords Non-esterified fatty acids, glycogenolysis, gluconeogenesis, insulin, liver, nuclear magnetic resonance
Increased endogenous glucose production (EGP) could contribute to fasting hyperglycaemia in Type II (non-insulin-dependent) diabetes mellitus and could result from increased rates of glycogenolysis

Received: 13 October 2000 and in revised form: 29 November 2000

Corresponding author: Michael Roden, MD, Divison of Endocrinology and Metabolism, Department of Internal Medicine III, University of Vienna Medical School, General Hospital of Vienna, Währinger Gürtel 18-20, A-1090 Vienna, Austria Abbreviations: EGP, Endogenous glucose production; GNG, gluconeogenesis; SRIF, somatostatin; NMR, nuclear magnetic resonance. or gluconeogenesis (GNG) or both. Increased GNG in Type II diabetes was observed by splanchnic balance [1] and ${ }^{13} \mathrm{C}$ nuclear magnetic resonance (NMR) spectroscopy techniques [2].

Non-esterified fatty acids (NEFA) not only induce peripheral insulin resistance [3-7], but could also be involved in the disturbance of hepatic glucose metabolism in Type II diabetes. Fasting plasma NEFA are frequently increased in Type II diabetes [8] and correlate with the magnitude of hyperglycaemia and EGP $[9,10]$. Moreover, NEFA are probably responsible for the indirect effect of insulin in suppressing EGP in dogs [11,12] and in humans [13]. How NEFA control the liver in humans is, however, still under de- 


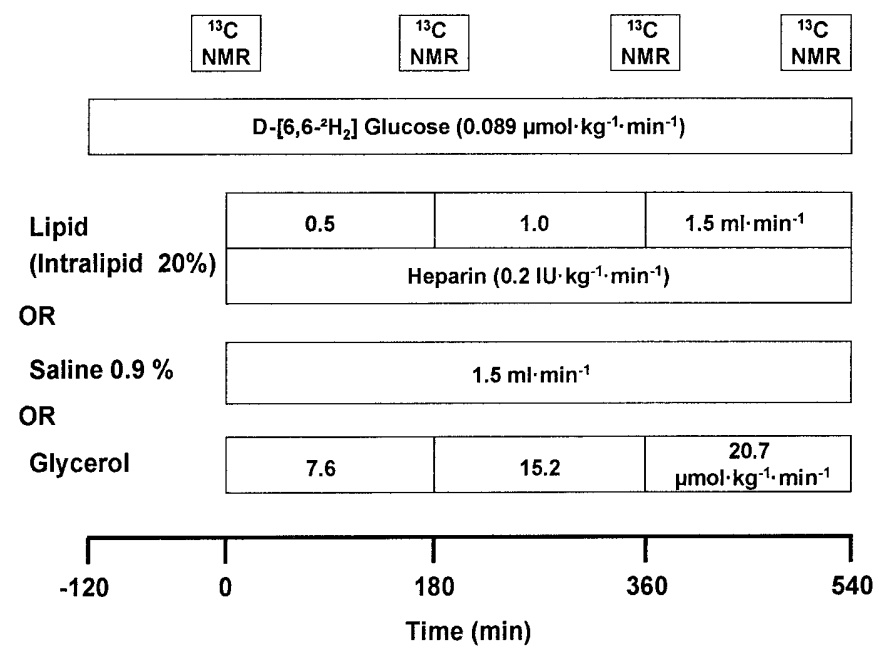

Fig. 1. Flow sheet of the experimental procedures in three different protocols (lipid, saline, glycerol). ${ }^{13} \mathrm{C}$ NMR defines liver glycogen measurements by ${ }^{13} \mathrm{C}$ nuclear magnetic resonance spectroscopy.

bate. Lipid/heparin infusions increased EGP during somatostatin (SRIF)-insulin clamps [14,15] but not after an overnight fast [16]. Similarly, nicotinic acid or its derivatives, which inhibit lipolysis, decreased basal EGP in some $[17,18]$ but not in other studies $[19,20]$. Contradictory effects of NEFA on GNG contributing to EGP have also been reported $[16,18,20-22]$. Differences between these studies are mainly attributed to NEFA-induced insulin secretion counterbalancing a stimulatory effect of NEFA on EGP [15] or to a lipid-associated rise in plasma glycerol, possibly the major gluconeogenic substrate under these conditions, or to both [1]. Finally, NEFA could evoke reciprocal changes of GNG and glycogenolysis which could prevent any increase in EGP $[16,18]$.

This study examines the effects of NEFA compared with those of glycerol on net hepatic glycogen breakdown, rates of EGP, and rates of GNG under post-absorptive conditions by combining ${ }^{13} \mathrm{C}$ nuclear magnetic resonance (NMR) spectroscopy with D$\left[6,6-{ }^{2} \mathrm{H}_{2}\right]$ glucose infusion in vivo [23-26].

\section{Subjects and methods}

Subjects. Seven healthy men (age range: 21-33 years; BMI: $21.7 \pm 1.1 \mathrm{~kg} / \mathrm{m}^{2}$ ) without a family history of diabetes mellitus, lipid or bleeding disorders volunteered to ingest a carbohydrate-rich, weight maintaining diet and to refrain from strenuous physical exercise for at least 3 days, then fasted overnight for $12 \mathrm{~h}$ before the experiments were carried out. No changes in diet, weight and lifestyle were recorded from the time of recruitment until completion of all studies. All subjects gave their informed, written consent to the protocols which were reviewed and approved by the ethics committee of the University of Vienna Medical School.
Study protocols. At 07:00 hours $(=-120 \mathrm{~min})$ catheters were inserted in the antecubital veins of the right and left arm of volunteers for blood sampling and infusions and an infusion of $\mathrm{D}-\left[6,6-{ }^{2} \mathrm{H}_{2}\right]$ glucose [bolus: $6.611(\mu \mathrm{mol} / \mathrm{kg}) \times$ body weight $(\mathrm{kg}) \times$ fasting blood glucose $(\mu \mathrm{mol} / \mathrm{l}) / 500(\mu \mathrm{mol} / \mathrm{l})$, continuous infusion: $0.089(\mu \mathrm{mol} / \mathrm{kg}) \times$ body weight $(\mathrm{kg}) /(\mathrm{min}) ; 99 \%$ enriched (Cambridge Isotope Lab, Andover, Mass., USA)] was started (Fig. 1). All subjects were studied (A) during Intralipid $20 \%$ (a generous gift from Kabi Pharmacia, Uppsala, Sweden) and heparin (bolus: $200 \mathrm{IU}$; continuously: $0.2 \mathrm{IU} \cdot \mathrm{kg}^{-1} \cdot \mathrm{min}^{-1}$ ) infusion to stepwise increase plasma NEFA concentrations (lipid protocol) and (B) during saline infusion providing control conditions (saline protocol). The procedures were done in a random order. Five subjects were studied again while plasma glycerol concentrations (glycerol protocol) were increased stepwise. All studies were carried out in intervals of 2 to 8 weeks. In all studies blood samples were taken every $90 \mathrm{~min}$, chilled, centrifuged and the supernatants stored at $-20^{\circ} \mathrm{C}$ until hormones and metabolites were measured.

Analytical procedures. Plasma glucose was measured on a Glucose analyser II (Beckman Instr., Fullerton, Calif.,USA). Plasma NEFA (Wako Chem., Neuss, Germany; intra-assay and inter-assay coefficients of variance CV: $4.3 \%$ and $5.7 \%$ ) and glycerol (Boehringer-Mannheim, Mannheim, Germany; CV: $2.0 \%$ and $3.4 \%$ ) were quantified enzymatically. Plasma insulin (Pharmacia-Upjohn, Uppsala, Sweden; CV: $<8 \%$ ), C peptide (CIS, Gif-Sur-Yvette, France; CV: $<9 \%$ ) and glucagon (Serono Diagnostics, Freiburg, Germany; $\mathrm{CV}:<8 \%$ ) were measured by radioimmunoassay (RIA). Plasma cortisol $(\mathrm{CV}:<6 \%)$ was quantified following extraction and charcoaldextran separation by RIA [27].

Gas chromatography-mass spectrometry. Plasma glucose was derivatized to the penta-acetate after $\mathrm{Ba}(\mathrm{OH})_{2}-\mathrm{ZnSO}_{4}$ deproteinization and semipurification by anion/cation exchange chromatography (AG1-8X, AG50W-8X; Bio-Rad Laboratories, Richmond, Calif., USA) [24]. The gas chromatography (GC)-mass spectrometry analysis was done on a HewlettPackard 5890 gas chromatograph (HP-1 capillary column, $12 \mathrm{~m} \times 0.2 \mathrm{~mm} \times 0.33 \mu \mathrm{m}$ film thickness) interfaced to a Hewlett-Packard 5971A mass selective detector operating in the electron impact ionization mode. For glucose penta-acetate, $\mathrm{GC}$ analysis was isothermal at $200^{\circ} \mathrm{C}$. Selected ion monitoring was used to quantify enrichments in various molecular ion fragments. The $M+2$ enrichment in $\left[6,6-{ }^{2} \mathrm{H}_{2}\right]$ glucose was measured from the mass-to-charge ratio ( $m: z)$ ratio of 202 to 200 of the fragment ion consisting of C2-C6 [28].

${ }^{13}$ C NMR spectroscopy. Liver glycogen concentrations were measured in all subjects from -30 until $+30,150$ to 210,330 to 390 and from 460 to $540 \mathrm{~min}$ using in vivo ${ }^{13} \mathrm{C}$ NMR spectroscopy on a 3-T Medspec 30/80-DBX system (Bruker Medical, Ettlingen, Germany) installed at the General Hospital of Vienna, Austria. Subjects were lying in the supine position in the magnet with the $10-\mathrm{cm}$ circular coil [double-tuned, ${ }^{1} \mathrm{H}(125.6$ $\left.\mathrm{MHz}),{ }^{13} \mathrm{C}(31.5 \mathrm{MHz})\right]$ positioned rigidly over the lateral aspect of the liver. The liver borders were measured by percussion and the correct position of the coil was confirmed with a multi-slice gradient echo image. Magnetic field homogeneity was optimized on the water signal to a line width of 60 to 80 $\mathrm{Hz}$. Spectra were acquired using a modified ID-ISIS sequence [23] without ${ }^{1} \mathrm{H}$ decoupling (pulse length $=150 \mu \mathrm{s} / 135^{\circ}$ in the coil plane, $\mathrm{TR}=150 \mathrm{~ms}$, acquisition time $=25.6 \mathrm{~ms}$, NS $=$ 5000 , total scan time $13 \mathrm{~min}$ ). Spectra were zero filled to $4 \mathrm{k}$, gaussian and exponentially filtered and phase-corrected manually. Hepatic glycogen was measured by integrating the $\mathrm{C} 1$ gly- 
Table 1. Plasma concentrations (means \pm SEM) of glucose $(\mathrm{mmol} / \mathrm{l})$, glucagon $(\mathrm{pg} / \mathrm{ml})$ and cortisol $(\mu \mathrm{g} / \mathrm{dl})$ and rates of endogenous glucose production (EGP, means \pm SEM) $(\mu \mathrm{mol} \cdot$

\begin{tabular}{|c|c|c|c|c|c|}
\hline & & $0 \min$ & $180 \mathrm{~min}$ & $360 \mathrm{~min}$ & $540 \mathrm{~min}$ \\
\hline Glucose & $\begin{array}{l}\text { Lipid } \\
\text { Glycerol } \\
\text { Saline }\end{array}$ & $\begin{array}{l}4.9 \pm 0.1 \\
4.9 \pm 0.1 \\
5.0 \pm 0.1\end{array}$ & $\begin{array}{l}4.8 \pm 0.1^{b} \\
4.9 \pm 0.1 \\
4.7 \pm 0.1^{b}\end{array}$ & $\begin{array}{l}4.6 \pm 0.2^{b} \\
4.9 \pm 0.2^{c} \\
4.6 \pm 0.1^{b}\end{array}$ & $\begin{array}{l}4.5 \pm 0.1^{b} \\
4.8 \pm 0.2^{\mathrm{c}} \\
4.5 \pm 0.1^{\mathrm{b}}\end{array}$ \\
\hline Glucagon & $\begin{array}{l}\text { Lipid } \\
\text { Glycerol } \\
\text { Saline }\end{array}$ & $\begin{array}{l}144 \pm 16 \\
166 \pm 28 \\
143 \pm 20\end{array}$ & $\begin{array}{l}142 \pm 27 \\
150 \pm 25 \\
132 \pm 17\end{array}$ & $\begin{array}{l}139 \pm 21 \\
148 \pm 28 \\
125 \pm 21\end{array}$ & $\begin{array}{l}136 \pm 20 \\
143 \pm 26 \\
123 \pm 20\end{array}$ \\
\hline EGP & $\begin{array}{l}\text { Lipid } \\
\text { Glycerol } \\
\text { Saline }\end{array}$ & $\begin{array}{l}14.7 \pm 1.0 \\
14.3 \pm 0.6 \\
13.8 \pm 1.0\end{array}$ & $\begin{array}{l}12.4 \pm 1.4 \\
14.0 \pm 0.7 \\
12.1 \pm 1.0\end{array}$ & $\begin{array}{l}11.3 \pm 1.2^{\mathrm{b}} \\
14.9 \pm 1.5 \\
11.8 \pm 1.1^{\mathrm{a}}\end{array}$ & $\begin{array}{l}10.1 \pm 1.0^{\mathrm{b}} \\
15.7 \pm 2.1^{\mathrm{d}} \\
10.9 \pm 1.1^{\mathrm{b}}\end{array}$ \\
\hline
\end{tabular}

${ }^{\mathrm{a}} p<0.05,{ }^{\mathrm{b}} p<0.01$ vs basal

${ }^{\mathrm{c}} p<0.05$ glycerol vs lipid, vs saline

${ }^{\mathrm{d}} p<0.001$ glycerol vs lipid, vs saline

cogen doublet at $100.5 \mathrm{ppm}$ using the same frequency bandwidth for all spectra $( \pm 300 \mathrm{~Hz})$. The absolute quantity of the hepatic glycogen concentration was calculated by comparing the peak integral with that of a glycogen standard obtained under identical conditions. Corrections for loading and sensitive volume of the coil were made.

Liver volume. Liver volumes were measured in a $1.5 \mathrm{~T}$ Vision imager (Siemens, Germany) using a body array coil and inphase and post-phase multislice FLASH imaging sequences. Slice number and position was chosen to cover the whole organ. Liver tissue was manually segmented and the area of each region of interest was measured in each slice. Areas were added and multiplied by the sum of slice thickness $(0.8 \mathrm{~mm})$ and interslice distance $(8 \mathrm{~mm})$.

Calculations and data analysis. Rates of EGP were calculated from the infusion rate of $\mathrm{D}-\left[6,6-{ }^{2} \mathrm{H}_{2}\right]$ glucose and its enrichment divided by the atom percent enrichment of plasma $\mathrm{D}-[6,6-$ ${ }^{2} \mathrm{H}_{2}$ ]glucose less the infusion rate. Isotopic steady state was confirmed by repeated measurements of deuterium enrichments in 15 min intervals. Rates of net glycogen breakdown were calculated for each subject from linear regression of the glycogen concentration-time curves of over $9 \mathrm{~h}$. Rates of gluconeogenesis were calculated from the difference between EGP and the net rates of hepatic glycogen breakdown. All data are presented as means \pm SEM. One-way Anova with Bartlett's test for equal variances and post hoc testing by the Bonferroni and the Newman-Keuls test was used for statistical comparisons between and within the different groups. The paired student's $t$-test was used for statistical comparisons within the time courses of the experiments. Statistical significance of differences was considered at $p$ values of less than 0,05. All calculations were done using the Sigma Stat software package (Jandel Corporation, San Rafael, Calif., USA).

\section{Results}

Plasma glucose. Plasma glucose concentrations slowly declined by about $10 \%$ from baseline values until the end of lipid and saline protocols $(p<0.01$; Ta- $\mathrm{kg}^{-1} \cdot \mathrm{min}^{-1}$ ) during infusion of lipid/heparin (lipid, $n=7$ ), glycerol (glycerol, $n=5$ ) and normal saline (saline, $n=7$ )

ble 1). During glycerol infusion, plasma glucose did not change from baseline and were about $10 \%$ higher than during lipid $(p<0.05)$ and saline protocols $(p<0.01)$.

Plasma NEFA and glycerol. Plasma NEFA concentrations rose to about $2.2 \mathrm{mmol} / \mathrm{l}$ during lipid/heparin infusion but did not change from baseline values $(\sim 0.29 \mathrm{mmol} / \mathrm{l})$ during saline and glycerol protocols (Fig. 2). Plasma glycerol concentrations were about $0.18 \mathrm{mmol} / \mathrm{l}$ at baseline, increased $(p<0.001)$ about 2.5 -fold and about 8-fold during lipid/heparin and glycerol protocols, respectively, but did not change during the saline protocol (Fig. 1).

Plasma insulin, C peptide, glucagon and cortisol. During the saline and glycerol tests, plasma insulin concentrations decreased continuously until $540 \mathrm{~min}$ $(p<0.05)$ (Fig. 2). In the last 3 hours of lipid infusion, plasma insulin increased by about $25 \%(p<0.05)$ above baseline and was about twofold higher than during saline and glycerol infusion at $540 \mathrm{~min}$ $(p<0.01)$. Plasma $\mathrm{C}$ peptide concentrations continuously decreased by about $40 \%(p<0.01)$ and about $30 \%(p<0.05)$ during saline and glycerol infusion, respectively (Fig. 2). After $540 \mathrm{~min}$ of lipid infusion, plasma C-peptide concentrations had increased by about $30 \% \quad(p<0.05)$ above baseline (zero time) and were about 2.2-fold higher than during the saline and the glycerol tests $(p<0.001)$. Plasma glucagon concentrations were similar at baseline and during all experiments (Table 1). Plasma cortisol decreased $(p<0.05)$ during glycerol, lipid and saline infusions (Table 1).

Endogenous glucose production. Rates of EGP were similar in all groups at zero time (Table 1). Endogenous glucose production showed a similar and contin- 


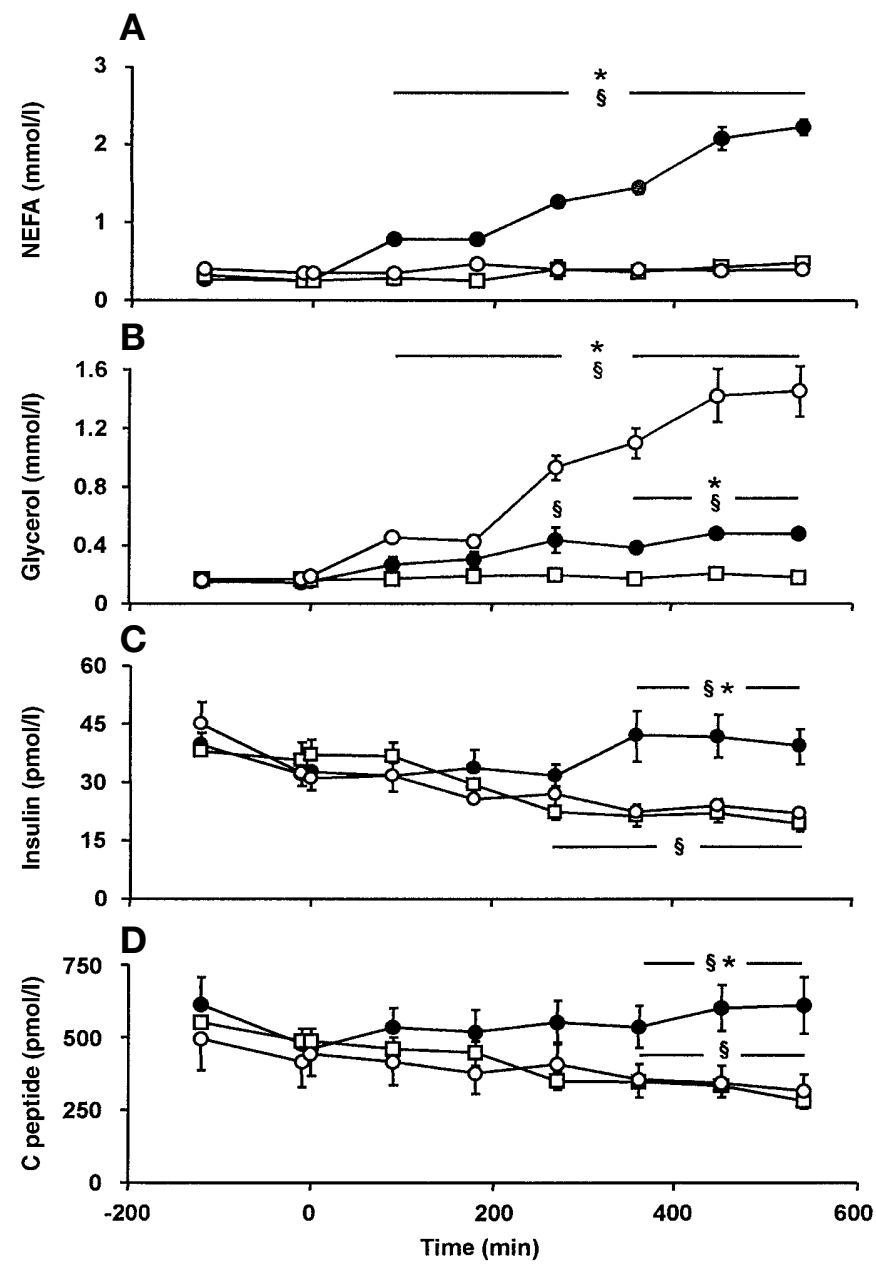

Fig. 2 A-D. Plasma concentrations (means \pm SEM) of non-esterified fatty acids (NEFA) (A) glycerol (B) insulin $(\mathbf{C})$ and C peptide (D) during infusion of saline $(n=7, \square)$, lipid/heparin $(n=7, \bigcirc)$ and glycerol $(n=5, \bigcirc) . * p<0.05$ vs saline; ${ }^{\S} p<0.05$ vs basal

uous decline $(p<0.005)$ during saline and lipid infusion. Only during glycerol infusion, did EGP not change from baseline values and was about $45 \%$ higher $(p<0.001)$ than during the saline and lipid protocols at $540 \mathrm{~min}$. The mean rates of EGP (0-540 min) were about $20 \%$ higher for the glycerol than for the saline $(p<0.01)$ and lipid protocols $(p<0.001)$.

Hepatic glycogen concentrations and net glycogen breakdown. Figure 3A depicts the time course of liver glycogen concentrations and the calculation of net rates of glycogen breakdown (glycogenolysis). Hepatic glycogen concentrations were not different at zero time $(\sim 219 \mathrm{mmol} / \mathrm{l}$ liver $)$ and linearly $\left(r^{2}=0.99, p<0.0001\right)$ declined to $150 \pm 30 \mathrm{mmol} / 1 \mathrm{liv}$ er during saline infusion at $540 \mathrm{~min}$. After $540 \mathrm{~min}$ of lipid infusion, hepatic glycogen concentrations declined only slightly $\left(r^{2}=0.046, p=0.07\right)$ to $206 \pm 19 \mathrm{mmol} / \mathrm{l}$ liver $(p<0.05)$, but were clearly
A

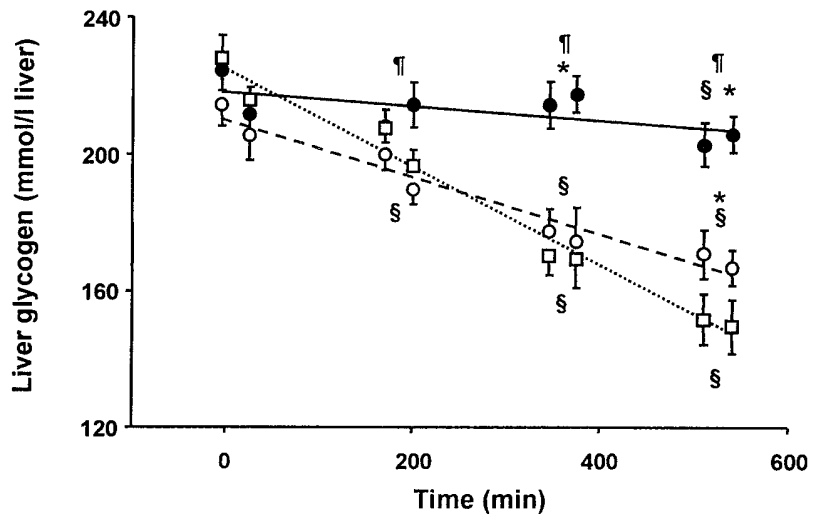

B

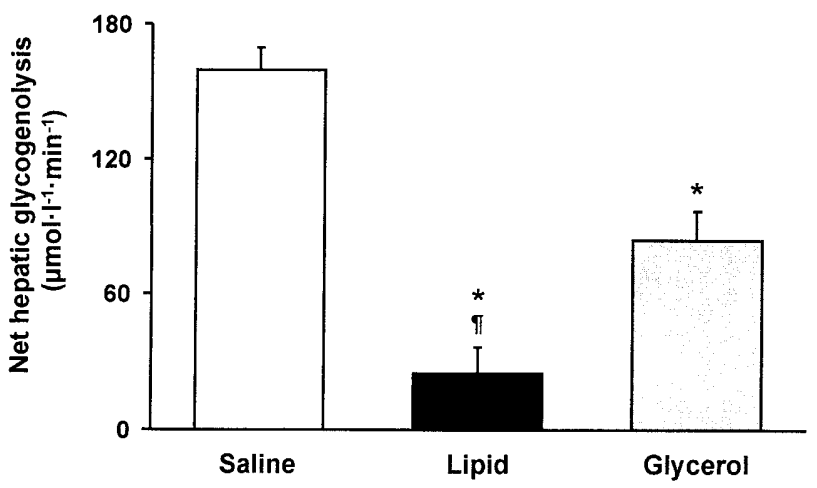

Fig.3 (A, B). Liver glycogen concentrations $(\mathbf{A})$ and rates of net glycogenolysis $(\mathbf{B})$ (means \pm SEM) during infusion of saline $(n=7, \square$, saline), lipid/heparin ( $n=7, \boldsymbol{\bullet}$, lipid) and glycerol $\left(n=5, \bigcirc\right.$, glycerol). ${ }^{*} p<0.05$ vs saline; ${ }^{\S} p<0.05$ vs basal, ${ }^{\mathbb{T}} p<0.05$ lipid vs glycerol

higher than in the saline protocol $(p<0.001)$. During glycerol infusion, hepatic glycogen concentrations $\left(r^{2}=0.97, \quad p<0.0001\right) \quad$ decreased linearly to $167 \pm 16 \mathrm{mmol} / \mathrm{l}$ liver $(p<0.001)$, being lower than in lipid $(p<0.001)$ but higher than in saline and glycerol protocols $(p<0.05$ each). Rates of net glycogen breakdown (glycogenolysis) were determined by line-fitting the glycogen-time course in the different protocols and calculated to be $159 \pm 10 \mu \mathrm{mol} \cdot \mathrm{l}^{-1}$. $\min ^{-1}\left(3.7 \pm 0.5 \mu \mathrm{mol} \cdot \mathrm{kg}^{-1} \cdot \mathrm{min}^{-1}\right)$ during the saline protocol (Fig. 3B). The increase of plasma NEFA during lipid infusion reduced glycogen breakdown by about $84 \%$ to $25 \pm 12 \mu \mathrm{mol} \cdot \mathrm{l}^{-1} \cdot \mathrm{min}^{-1}$ $\left(0.6 \pm 0.3 \mu \mathrm{mol} \cdot \mathrm{kg}^{-1} \cdot \mathrm{min}^{-1}\right) \quad(p<0.001$ vs saline $)$. Glycerol infusion decreased glycogen breakdown only by $46 \%$ to $84 \pm 12 \mu \mathrm{mol} \cdot 1^{-1} \cdot \min ^{-1}(2.0 \pm$ $\left.0.4 \mu \mathrm{mol} \cdot \mathrm{kg}^{-1} \cdot \mathrm{min}^{-1}\right)(p<0.01 \mathrm{vs}$ saline and lipid $)$.

Rates of net gluconeogenesis. Data of body weight $(71.1 \pm 3.7 \mathrm{~kg})$ and liver volume $(1.59 \pm 0.04$ liter $)$ were used to calculate net rates of GNG and glycogen breakdown. Net GNG (lipid $11.5 \pm 0.8 \mu \mathrm{mol} \cdot \mathrm{kg}^{-1}$. $\left.\mathrm{min}^{-1}\right)$ was higher in the lipid $(p<0.01)$ than in the saline protocol $\left(8.2 \pm 0.7 \mu \mathrm{mol} \cdot \mathrm{kg}^{-1} \cdot \mathrm{min}^{-1}\right)$ even though EGP stayed the same. Net GNG $\left(12.8 \pm 1.0 \mu \mathrm{mol} \cdot \mathrm{kg}^{-1} \cdot \mathrm{min}^{-1}\right)$ was higher during the 
high-dose glycerol infusion than during the saline infusion $(p<0.01)$.

\section{Discussion}

Net glycogen breakdown under control conditions (saline protocol) was about $159 \mu \mathrm{mol} \cdot \mathrm{l}^{-1} \cdot \mathrm{min}^{-1}$, which is similar to the rates $\left(\sim 163 \mu \mathrm{mol} \cdot \mathrm{l}^{-1} \cdot \mathrm{min}^{-1}\right.$ [2]; $200 \mu \mathrm{mol} \cdot \mathrm{l}^{-1} \cdot \mathrm{min}^{-1}$ [23]) reported for the fasted state $(12-21$ hours). Under these conditions, GNG accounted for $69 \%$ of EGP which is also in line with data obtained by ${ }^{13} \mathrm{C}$ NMR spectroscopy [2, $23,25]$ and slightly higher compared with the ${ }^{2} \mathrm{H}_{2} \mathrm{O}$ method [18, 25, 29]. Potential reasons for the lower estimates reported for mass isotope distribution analysis have been discussed recently [30-32].

We found that a plasma NEFA increase inhibits the postabsorptive decrease of hepatic glycogen contents so that net glycogen breakdown accounts for only $4 \%$ of EGP. Net hepatic glycogenolysis is also reduced to about $12 \%$ in Type II diabetic [2] and cirrhotic patients [25], who both have increased plasma NEFA concentrations. Recently, the increase of plasma NEFA was shown by the ${ }^{2} \mathrm{H}_{2} \mathrm{O}$ method to increase the contribution of GNG to glucose production $[18,22]$. When glycogenolysis was assessed indirectly, glycogenolysis contributed to EGP by about $21 \%$ during the post-acipimox rebound of plasma NEFA to about $1.8 \mathrm{~mol} / \mathrm{l}$ [18]. In the face of similar plasma NEFA concentrations, it is possible that the higher estimates of glycogenolysis and the lower contribution of GNG to EGP are caused by different plasma NEFA patterns or the effect of acipimox in itself, or both, on hepatic metabolism in their study. More likely, the difference can be explained by the fact that these methods measure different processes [25]. For glycogenolysis, ${ }^{13} \mathrm{C}$ NMR spectroscopy allows the direct measurement of the actual liver glycogen concentration and the mean rate of net glycogenolysis over the 9-h fasting period. The rate of net gluconeogenesis is therefore also the average for the whole period and is usually calculated using the rates of EGP at the end of that period only. Our study, however, measured EGP repetitively throughout the complete experimental period. These measurements showed only a minor decline from about 14 to about $11 \mu \mathrm{mol} \cdot \mathrm{kg}^{-1} \cdot \mathrm{min}^{-1}$ during lipid and saline infusions. We could therefore use the mean rates of EGP to calculate the contribution of GNG. Nevertheless, using the rates of EGP obtained during the last $3 \mathrm{~h}$ would have affected the calculation by only approximately $2 \%$. The ${ }^{2} \mathrm{H}_{2} \mathrm{O}$ method, on the other hand, measures rates of total hepatic glycogenolysis, i.e. net hepatic glycogenolysis + hepatic glycogen cycling. Although glycogen cycling is negligible in the fasting state in healthy subjects [26], it is relevant under hyperinsu- linaemic [26] or hyperglucagonaemic [5] conditions, and might occur during NEFA or glycerol increase or both [33].

Previous studies suggest that NEFA induces reciprocal changes in gluconeogenesis and glycogenolysis, i.e. hepatic autoregulation, resulting in constant EGP [16, 20, 34-37]. In contrast, some authors found that a reduction in plasma NEFA improves suppression of endogenous glucose production [17, 38, 39]. Those studies, however, did not quantify hepatic glycogen concentrations directly. Our results show that net changes in glycogen breakdown (lipid/heparin: $0.62 \pm 0.29$ vs saline: $\left.3.68 \pm 0.45 \mu \mathrm{mol} \cdot \mathrm{kg}^{-1} \cdot \mathrm{min}^{-1}\right)$ and GNG (11.46 \pm 0.83 vs $8.22 \pm 0.68 \mu \mathrm{mol} \cdot \mathrm{kg}^{-1}$. $\left.\mathrm{min}^{-1}\right)$ were almost identical in absolute terms $(-3.06$ $\mathrm{vs}+3.24 \mu \mathrm{mol} \cdot \mathrm{kg}^{-1} \cdot \mathrm{min}^{-1}$ ) suggesting that glycogenolysis and GNG contribute equally to keeping EGP constant $(12.08 \pm 1.02$ vs $11.90 \pm 0.78 \mu \mathrm{mol}$. $\left.\mathrm{kg}^{-1} \cdot \mathrm{min}^{-1}\right)$. Recently, the increase in GNG was reported to be less than the decrease in glycogenolysis $\left(\sim 3 \mathrm{vs} \sim 4.3 \mu \mathrm{mol} \cdot \mathrm{kg}^{-1} \cdot \mathrm{min}^{-1}\right)$ [18]. This could result from underestimating fractional GNG by the C5:C2 ratio to the extent that GNG increases during the course of the study. On the other hand, triose phosphate and pentose cycling as well as transaldolase reactions could each contribute by approximately $2 \%$ to overestimation of GNG from the $\mathrm{C} 5: \mathrm{C} 2$ ratio [40] but they should have no influence on ${ }^{13} \mathrm{C}$ NMR spectroscopy measurements [25]. Alternatively, NEFA could directly stimulate gluconeogenesis either by supplying the energy necessary for [41] or activating key enzymes of gluconeogenesis like pyruvate carboxylase, or both [42, 43] or phosphoenolpyruvate carboxykinase [44].

During plasma NEFA increase, plasma insulin and C-peptide concentrations increased in parallel indicating the stimulation of insulin secretion as reported previously in humans [15, 22, 45-48] and in rats [49]. When we consider that portal vein insulin is about 2.5 times the venous insulin and that portal vein contributes about $80 \%$ of the hepatic blood flow, liver sinusoidal insulin concentration was higher during lipid infusion $(\sim 83 \mathrm{pmol} / \mathrm{l})$ than during the saline $(\sim 50 \mathrm{pmol} / \mathrm{l})$ and glycerol $(\sim 53 \mathrm{pmol} / \mathrm{l})$ protocols. Such rise could have affected EGP [50-53] and play a part in restraining glycogenolysis [53]. Furthermore, the rise in insulin concentrations would probably not inhibit hepatic gluconeogenesis thus allowing NEFA to stimulate the process. Moreover, inhibition of hepatic glycogenolysis requires higher insulin concentrations in humans $[5,26,53]$. In addition, portal and also peripheral insulin concentrations are responsible for the hormone's inhibitory effect on the liver [53-55]. Thus, NEFA simultaneously reduces glycogenolysis and increases gluconeogenesis most likely by a direct action, although indirect effects on insulin secretion could also contribute to the effect. 
Finally, incrased gluconeogenesis during lipid/heparin infusion could also be the result of increased plasma concentrations [56] or the availability of glycerol, or both $[14,57]$,which is a direct gluconeogenic substrate under these conditions [58, 59]. Plasma glycerol concentrations matching those observed during lipid infusion $(\sim 0.48 \mathrm{mmol} / \mathrm{l})$ did not increase gluconeogenesis in healthy subjects [22]. Nevertheless, it cannot be ruled out that in the presence of increased NEFA and insulin, glycerol has some effect which it would not have alone. In this study, high plasma glycerol concentrations increased the rates of GNG to the extent observed during lipid/heparin infusion but were still less effective in reducing net glycogen breakdown. Glycerol-dependent GNG and net glycogen breakdown probably contributed to the higher rates of EGP in the glycerol study, which agrees with a previous study using nicotinic acid [60]. The correlation between plasma glycerol and GNG [61] indicates that the small rise of plasma glycerol concentrations during lipid infusion most likely did not cause the reduction in glycogenolysis. The increase of gluconeogenesis from glycerol in patients with Type II diabetes seems to be a consequence not only of accelerated lipolysis but also of increased intrahepatic conversion of glycerol to glucose [62].

In conclusion, the rise in plasma NEFA simultaneously inhibits net hepatic glycogen breakdown and gluconeogenesis without affecting endogenous glucose production. This effect is, however, not caused by increased glycerol availability alone, because very high glycerol concentrations were required for a similar increase in gluconeogenesis.

The results therefore suggest that the control of the gluconeogenic rate and the conservation of liver glycogen stores is lipid-dependent in healthy humans.

Acknowledgements. We thank the staff of the Metabolic Unit (A. Hofer, O.H. Lentner and D. Weghuber) and the staff of the laboratory of the Division of Clinical Endocrinology and Metabolism, Department of Internal Medicine III, as well as V. Walton (Howard Hughes Medical Institute) for their skilful work. We also thank Professors H. Imhof, MD, MR Unit and E. Moser, PhD, Institute of Medical Physics, University of Vienna, for their cooperation and support. These studies were supported by grants from the Austrian Science Foundation (FWF, P13213-MOB) to M. Roden, by the Austrian National Bank (ÖNB, 8196) to W. Waldhäusl and M. Roden, and by the National Institutes of Health (ROI DK-49230, P30 DK45735) to G I Shulman (Howard Hughes Medical Institute). H. Stingl was supported by an educational grant of the Austrian Academy of Sciences (427/1997).

\section{References}

1. Waldhäusl W, Bratusch-Marrain P, Gasic S, Korn A, Nowotny $P$ (1982) Insulin production rate, hepatic insulin retention and splanchnic carbohydrate metabolism after oral glucose inges- tion in hyperinsulinaemic Type 2 (non-insulin-dependent) diabetes mellitus. Diabetologia 23: 6-15

2. Magnusson I, Rothman DL, Katz LD, Shulman RG, Shulman GI (1992) Increased rate of gluconeogenesis in type II diabetes mellitus. $\mathrm{A}^{13} \mathrm{C}$ nuclear magnetic resonance study. J Clin Invest 90: $1323-1327$

3. Boden G (1997) Role of fatty acids in the pathogenesis of insulin resistance and NIDDM. Diabetes 46: 3-10

4. Kelley DE, Mokan M, Simoneau JA, Mandarino LJ (1993) Interaction between glucose and free fatty acid metabolism in human skeletal muscle. J Clin Invest 92: 91-98

5. Roden M, Perseghin G, Petersen KF et al. (1996) The roles of insulin and glucagon in the regulation of hepatic glycogen synthesis and turnover in humans. J Clin Invest 97: 642-648

6. Roden M, Krssak M, Stingl H et al. (1999) Rapid impairment of skeletal muscle glucose transport/ phosphorylation by free fatty acids in man. Diabetes 48: 358-364

7. Dresner A, Laurent D, Marcucci M et al. (1999) Effects of free fatty acids on glucose transport and IRS-1-associated phosphaditylinositol 3-kinase activity. J Clin Invest 103: 253-259

8. Reaven GM, Hollenbeck C, Jeng CY, Wu MS, Chen YD (1988) Measurement of plasma glucose free fatty acid, lactate, and insulin for $24 \mathrm{~h}$ in patients with NIDDM. Diabetes 37: 1020-1024

9. Bogardus C, Lillioja S, Howard BV, Reaven G, Mott D (1984) Relationships between insulin secretion, insulin action, and fasting plasma glucose concentration in nondiabetic and noninsulin-dependent diabetic subjects. J Clin Invest 74: 1238-1246

10. Golay A, Swislocki AL, Chen YD, Reaven GM (1987) Relationships between plasma-free fatty acid concentration, endogenous glucose production, and fasting hyperglycaemia in normal and non-insulin-dependent diabetic individuals. Metabolism 36: 692-696

11. Sindelar DK, Chu CA, Rohlie M, Neal DW, Swift LL, Cherrington AD (1997) The role of fatty acids in mediating the effects of peripheral insulin on hepatic glucose production in the conscious dog. Diabetes 46: 187-196

12. Rebrin K, Steil GM, Mittelman SD, Bergman RN (1996) Causal linkage between insulin suppression of lipolysis and suppression of liver glucose output in dogs. J Clin Invest 98: 741-749

13. Lewis GF, Vranic M, Harley P, Giacca A. (1997) Fatty acids mediate the acute extrahepatic effects of insulin on hepatic glucose production in humans. Diabetes 46: 1111-1119

14. Ferrannini E, Barrett EJ, Bevilacqua S, DeFronzo RA (1983) Effect of fatty acids on glucose production and utilization in man. J Clin Invest 72: 1737-1747

15. Boden G Jadali F (1991) Effects of lipid on basal carbohydrate metabolism in normal men. Diabetes 40: 686-692

16. Clore JN, Glickman PS, Nestler JE, Blackard WG (1991) In vivo evidence for hepatic autoregulation during NEFA-stimulated gluconeogenesis in normal humans. Am J Physiol 261: E425-E429

17. Fulcher GR, Walker M, Catalano C, Agius L, Alberti KG (1992) Metabolic effects of suppression of nonesterified fatty acid levels with acipimox in obese NIDDM subjects. Diabetes 41: 1400-1408

18. Chen X, Iqbal N, Boden G (1999) The effects of free fatty acids on gluconeogenesis and glycogenolysis in normal subjects. J Clin Invest 103: 365-372

19. Vaag A, Skott P, Damsbo P, Gall MA, Richter EA, Beck-Nielsen H (1991) Effect of the antilipolytic nicotinic acid analogue acipimox on whole-body and skeletal muscle glucose metabolism in patients with non-insulin-dependent diabetes mellitus. J Clin Invest 88: 1282-1290

20. Puhakainen I, Yki-Järvinen H (1993) Inhibition of lipolysis decreases lipid oxidation and gluconeogenesis from lactate but not fasting hyperglycaemia or total hepatic glucose production in NIDDM. Diabetes 42: 1694-1699

21. Fery F, Plat L, Melot C, Balasse EO (1996) Role of fat-derived substrates in the regulation of gluconeogenesis during fasting. Am J Physiol 270: E822-E830 
22. Roden M, Stingl H, Chandramouli V et al. (2000) Effects of free fatty acid elevation on postabsorptive endogenous glucose production and gluconeogenesis in man. Diabetes 49: 701-707

23. Rothman DL, Magnusson I, Katz ID, Shulman RG, Shulman GI (1991) Quantitation of hepatic glycogenolysis and gluconeogenesis in fasting humans with ${ }^{13} \mathrm{C}$ NMR. Science 254 : 573-576

24. Petersen KF, Price T, Cline GW, Rothman DL, Shulman GI (1996) Contribution of net hepatic glycogenolysis to glucose production during the early postprandial period. Am J Physiol 270: E186-E191

25. Petersen KF, Krssak M, Navarro V et al. (1999) Contributions of net hepatic glycogenolysis and gluconeogenesis to glucose production in cirrhosis. Am J Physiol 276: E529-E535

26. Petersen KF, Laurent D, Rothman DL, Cline GW, Shulman GI (1998) Mechanism by which glucose and insulin inhibit net hepatic glycogenolysis in humans. J Clin Invest 101: 1203-1209

27. Waldhäusl W, Herkner K, Nowotny P, Bratusch-Marrain P (1978) Combined 17 alpha- and 18-hydroxylase deficiency associated with complete male pseudohermaphroditism and hypoaldosteronism. J Clin Endocrinol Metab 46: 236-246

28. Caprioli RM, Seifert WE Jr. (1973) Direct analysis of ${ }^{18} \mathrm{O}$ in glucose by mass spectrometry. Biochim Biophys Acta 297: 213-219

29. Landau BR, Wahren J, Chandramouli V, Schumann WC, Ekberg K, Kalhan SC (1996) Contributions of gluconeogenesis to glucose production in the fasted state. J Clin Invest 98: 378-385

30. Landau BR (1999) Limitations in the use of [U-13 C]glucose to estimate gluconeogenesis. Am J Physiol 277: E408-E413

31. Kelleher JK (1999) Estimating gluconeogenesis with [U$\left.{ }^{13} \mathrm{C}\right]$ glucose: molecular condensation requires a molecular approach. Am J Physiol 277: E395-E400

32. Radziuk J, Lee WN (1999) Measurement of gluconeogenesis and mass isotopomer analysis based on $\left[\mathrm{U}-{ }^{13} \mathrm{C}\right]$ glucose. Am J Physiol 277: E199-E207

33. Hellerstein MK, Neese RA, Letscher A, Linfoot P, Turner S (1997) Hepatic glucose-6-phosphatase flux and glucose phosphorylation, cycling, irreversible disposal, and net balance in vivo in rats. Measurement using the secreted glucuronate technique. Metabolism 46: 1390-1398

34. Clore JN, Glickman PS, Helm ST, Nestler JE, Blackard WG (1991) Evidence for dual control mechanism regulating hepatic glucose output in nondiabetic men. Diabetes 40: 1033-1040

35. Fanelli C, Calderone S, Epifano L et al. (1993) Demonstration of a critical role for free fatty acids in mediating counterregulatory stimulation of gluconeogenesis and suppression of glucose utilization in humans. J Clin Invest 92: 1617-1622

36. Jenssen T, Nurjhan N, Consoli A, Gerich JE (1990) Failure of substrate-induced gluconeogenesis to increase overall glucose appearance in normal humans. Demonstration of hepatic autoregulation without a change in plasma glucose concentration. J Clin Invest 86: 489-497

37. Wahren J, Hagenfeldt L, Felig P (1975) Splanchnic and leg exchange of glucose, amino acids, and free fatty acids during exercise in diabetes mellitus. J Clin Invest 55: 1303-1314

38. Taskinen MR, Sane T, Helve E, Karonen SL, Nikkila EA, YkiJarvinen H (1989) Bedtime insulin for suppression of overnight free-fatty acid, blood glucose, and glucose production in NIDDM. Diabetes 38: 580-588

39. Santomauro AT, Boden G, Silva ME et al. (1999) Overnight lowering of free fatty acids with Acipimox improves insulin resistance and glucose tolerance in obese diabetic and nondiabetic subjects. Diabetes 48: 1836-1841

40. Chandramouli V, Ekberg K, Schumann WC, Wahren J, Landau BR (1999) Origins of the hydrogen bound to carbon 1 of glucose in fasting: significance in gluconeogenesis quantitation. Am J Physiol 277: E717-E723
41. Youn H, Bergman RN (1990) Enhancement of hepatic glycogen by gluconeogenic precursors: substrate flux or metabolic control? Am J Physiol 258: E899-E906

42. Williamson JR, Kreisberg RA, Felts PW (1966) Mechanism for the stimulation of gluconeogenesis by fatty acids in perfused rat liver. Proc Natl Acad Sci USA 56: 247-254

43. Bahl JJ, Matsuda M, DeFronzo RA, Bressler R (1997) In vitro and in vivo suppression of gluconeogenesis by inhibition of pyruvate carboxylase. Biochem Pharmacol 53: 67-74

44. Antras-Ferry J, Robin P, Robin D, Forest C (1995) Fatty acids and fibrates are potent inducers of transcription of the phosphenolpyruvate carboxykinase gene in adipocytes. Eur J Biochem 234: 390-396

45. Pelkonen R, Miettinen TA, Taskinen MR, Nikkilä EA (1968) Effect of acute elevation of plasma glycerol, triglyceride and NEFA levels on glucose utilization and plasma insulin. Diabetes 17: 76-82

46. Boden G, Chen X, Rosner J, Barton M (1995) Effects of a 48-h fat infusion on insulin secretion and glucose utilization. Diabetes 44: 1239-1242

47. Segall L, Lameloise N, Assimacopoulos-Jeannet F et al. (1999) Lipid rather than glucose metabolism is implicated in altered insulin secretion caused by oleate in INS-1 cells. Am J Physiol 277: E521-E528

48. Carpentier A, Mittelman SD, Lamarche B, Bergman RD, Giacca A, Lewis GF (1999) Acute enhancement of insulin secretion by NEFA in humans is lost with prolonged NEFA elevation. Am J Physiol 276: E1055-E1066

49. Stein DT, Esser V, Stevenson BE et al. (1996) Essentiality of circulating fatty acids for glucose-stimulated insulin secretion in the fasted rat. J Clin Invest 97: 2728-2735

50. Rizza RA, Mandarino LJ, Gerich JE (1981) Dose-response characteristics for effects of insulin on production and utilization of glucose in man. Am J Physiol 240: E630-E639

51. DeFronzo RA, Ferrannini E, Hendler R, Felig P, Wahren J (1983) Regulation of splanchnic and peripheral glucose uptake by insulin and hyperglycaemia in man. Diabetes $32: 35-45$

52. Groop LC, Bonadonna RC, DelPrato S et al. (1989) Glucose and free fatty acid metabolism in non-insulin-dependent diabetes mellitus. Evidence for multiple sites of insulin resistance. J Clin Invest 84: 205-213

53. Cherrington A-D, Edgerton D, Sindelar (1998) The direct and indirect effects of insulin on hepatic glucose production in vivo. Diabetologia 41: 987-996

54. Prager R, Wallace P, Olefsky JM (1987) Direct and indirect effects of insulin to inhibit hepatic glucose output in obese subjects. Diabetes 36: 607-611

55. Lewis GF, Zinman B, Groenewoud Y, Vranic M, Giacca A (1996) Hepatic glucose production is regulated both by direct and extrahepatic effects of insulin in humans. Diabetes 45: 454-462

56. Lee KU, Lee HK, Koh CS, Min HK (1988) Artificial induction of intravascular lipolysis by lipid-heparin infusion leads to insulin resistance in man. Diabetologia 31: 285-290

57. Podolin DA, Wie Y, Pagliassotti MJ (1999) Effects of a high-fat diet and voluntary wheel running on gluconeogenesis and lipolysis in rats. J Appl Physiol 86: 1374-1380

58. Bortz WM, Paul P, Haff AC, Holmes WL (1972) Glycerol turnover and oxidation in man. J Clin Invest 51: 1537-1546

59. Baba H, Zhang XJ, Wolfe RR (1995) Glycerol gluconeogenesis in fasting humans. Nutrition 11: 149-153

60. Jahoor F, Klein S, Wolfe R (1992) Mechanism of regulation of glucose production by lipolysis in humans. Am J Physiol 262: E353-E358

61. Previs SF, Cline GW, Shulman GI (1999) A critical evaluation of mass isotopomer distribution analysis of gluconeogenesis in vivo. Am J Physiol 277: E154-E160

62. Puhakainen I, Koivisto VA, Yki-Jarvinen H (1992) Lipolysis and gluconeogenesis from glycerol are increased in patients with noninsulin-dependent diabetes mellitus. J Clin Endocrinol Metab 75: 789-794 